\title{
Regional oceanographic features and hydrothermal activity influence protist diversity and biogeography in the Okinawa Trough
}

\author{
Margaret Mars Brisbin ${ }^{a^{*}}$, Asa E. Conover ${ }^{a}$, Satoshi Mitarai ${ }^{\mathrm{a}}$
}

5

a Marine Biophysics Unit, Okinawa Institute of Science and Technology Graduate University, Okinawa, Japan

*Corresponding Author, margaret.marsbrisbin@oist.jp

\section{Abstract}

Microbial eukaryotes (protists) contribute substantially to ecological functioning in marine ecosystems, but factors shaping protist diversity, such as dispersal barriers and environmental selection, remain difficult to parse. Deep-sea water masses, which form geographic barriers, and hydrothermal vents, which represent isolated productivity hotspots, are ideal opportunities for studying the effects of dispersal barriers and environmental selection on protist communities. The Okinawa Trough, a deep, back-arc spreading basin, contains distinct water masses in the bottom waters of northern and southern regions and at least twenty-five active hydrothermal vents. In this study, we used metabarcoding to characterize protist communities from fourteen stations spanning the length of the Okinawa Trough, including three hydrothermal vent sites. Significant differences in community structure reflecting regional oceanography and water mass composition were present, indicating the importance of geographic factors in shaping protist communities. Protist communities in bottom waters affected by hydrothermal activity were significantly different from communities in other bottom waters, suggesting that environmental factors can be especially important in shaping community composition under specific conditions. Amplicon sequence variants that were enriched in hydrothermally influenced bottom waters largely derived from cosmopolitan protists that were present, but rare, in other near-bottom samples, thus highlighting the importance of the rare biosphere. 
Protist diversity and biogeography in the Okinawa Trough

\section{Introduction}

Microbial unicellular eukaryotes (protists) are important contributors to all marine ecosystems, from the sunlit surface waters [1] to the deep, dark bathypelagic [2]. Extensive phylogenetic and functional diversity among protists-especially in extreme environments like the deep sea and hydrothermal vents [3] — has been revealed by high-throughput sequencing with environmental samples, but factors influencing protist community structure remain difficult to parse [4, 5]. Physicochemical factors, such as temperature, light and nutrient availability, have historically been regarded as having the strongest influence on microbial community structure, but geographic restrictionsbetween ocean basins [4] and water masses [5, 6] -and biological interactions [7] can also contribute substantially to shaping microbial community structure. Furthermore, physicochemical, biological, and geographical factors can vary in their relative influences on community structure at different depths and in different oceanic regions [8].

The Okinawa Trough (OT), a back-arc spreading basin (> $2000 \mathrm{~m}$ ) within the East China Sea, is an ideal environment to investigate factors shaping protist community structure. The Kuroshio Current, the western boundary current of the North Pacific subtropical gyre, enters the OT to the east of Taiwan, and transports warm, highsalinity water northward [9]. The bottom water in the southern OT is formed from Kuroshio Intermediate water (KIW), which is $55 \%$ high-salinity South China Sea Intermediate Water (SCSIW) and 45\% low-salinity North Pacific Intermediate Water (NPIW), flowing over the sill $(775 \mathrm{~m}$ ) east of Taiwan and into the southern OT [10]. Additional surface water and intermediate water are entrained into the OT through the Kerama Gap, which, with a sill depth of $1100 \mathrm{~m}$, is the deepest channel connecting the

55 OT and the Philippine Sea. NPIW consistently enters the deep regions of the OT through the Kerama Gap [11], increasing the contribution of NPIW to bottom waters in the northern OT to $65 \%$ [10]. However, surface flow in the Kerama Gap is periodically reversed, likely due to the arrival of mesoscale eddies from the interior of the North Pacific [11]. The topography and current structure in the OT lead to varying 
Protist diversity and biogeography in the Okinawa Trough

southern (45\% NPIW, 55\% SCSIW) and northern OT (65\% NPIW, 35\% SCSIW) and the Kerama Gap (75\% NPIW, 25\% SCSIW) [10], thus facilitating study of how water mass composition impacts on protist community structure.

As a back-arc spreading basin, there is extensive hydrothermal activity throughout the Okinawa Trough [12]. Twenty-five active OT hydrothermal vent sites are listed in The InterRidge Database v3.4 [13], but this figure likely remains an underestimate as new vents continue to be discovered [14, 15]. The hydrothermal vents in the OT are distinct from those found at mid-ocean ridges, primarily due to thick layers of terrigenous sediments overlaying vent sites. Compared to sediment-starved vent systems, OT vent fluids are typically low $\mathrm{pH}$ with high concentrations of $\mathrm{CO}_{2}, \mathrm{NH}_{4}{ }^{+}$, boron, iodine, potassium, lithium [16] and methane [17]. Unique physicochemical conditions associated with different vent systems-such as those associated with OT vents-give rise to heterogeneous biological communities [18], warranting careful study

75 of diverse hydrothermal systems. In addition, organic matter and inorganic nutrients resuspended by vents in the OT may locally increase microbial production in bottom waters [19]. However, vent fields in the Okinawa Trough have not been studied nearly as extensively as hydrothermal vents in other oceanic regions [12].

In this study, we present the first comprehensive survey of protist community

80 structure in the Okinawa Trough and Kuroshio Current. We analyzed protist community composition in replicate samples collected from the sea surface, subsurface chlorophyll maximum, middle water column, and bottom waters at sites spanning the entire length of the Okinawa Trough and within the Kerama Gap. In addition, bottom waters at three of our sampling sites were influenced by nearby hydrothermal vents, as evidenced by

85 increased turbidity, $\mathrm{CDOM}$ (colored dissolved organic matter), $\mathrm{NH}_{4}$, and total carbon concentrations—conditions typical of hydrothermal vent plumes in the OT [16, 20]. The main objectives of the study were to: (i) assess broad patterns in protist diversity in the Okinawa Trough and Kuroshio Current, (ii) determine the extent to which OT protist diversity is affected by regional ocean circulation and water mass composition, and (iii)

90 investigate the influence of hydrothermal activity on deep-sea protist communities in the OT. 
Protist diversity and biogeography in the Okinawa Trough

\section{Materials and Methods}

\section{Sampling locations}

95 Water samples were collected from 14 sites in the Okinawa Trough and Kerama Gap during the Japan Agency for Marine-Earth Science and Technology (JAMSTEC) MR1703C cruise from May 29 to June 13, 2017 (Figure 1). Stations 8, 9, 10, and 11 are located in the Southern Okinawa Trough (SOT); stations 3, 4, 2, 5 make up a transect of the Kerama Gap (KG) from east to west; stations 12, 13, 14, 15, 17, and 18 are in the

100 Northern Okinawa Trough (NOT) stations. Five stations are located near known active hydrothermal vent sites; station 10 is at the Hatoma Knoll [16], station 2 is at the ANA vent site of the Daisan-Kume Knoll [14], station 11 is near the Dai-Yon Yonaguni Knoll [21], station 5 is near the Higa vent site [14], and station 12 is near the Iheya North vent field [22]. Physicochemical data collected by in-situ sensors and chemical analysis of

105 water samples were used to discern whether or not samples were influenced by hydrothermal vent plumes. Vertical profiles from stations 2,10 , and 11 showed nearbottom turbidity and CDOM maxima (Supplemental Figure 1A), which is typical for OT vent plumes [16, 20]. In addition, nutrient analysis showed elevated $\mathrm{NH}_{4}$ concentrations in bottom water samples from stations 2 and 10, providing further evidence of

110 hydrothermal influence [16, 20] (Supplemental Figure 1B). Total carbon was only measured for samples from stations 2, 10,14, and 15; consistent with hydrothermal influence [16, 20], stations 2 and 10 exhibit near bottom peaks in carbon concentrations (Supplemental Figure 1C). Stations 2, 10 and 11 are, therefore, included in analyses aimed at determining how hydrothermal activity influences protist community structure in the OT, while the other sampling stations near vent sites are not. 


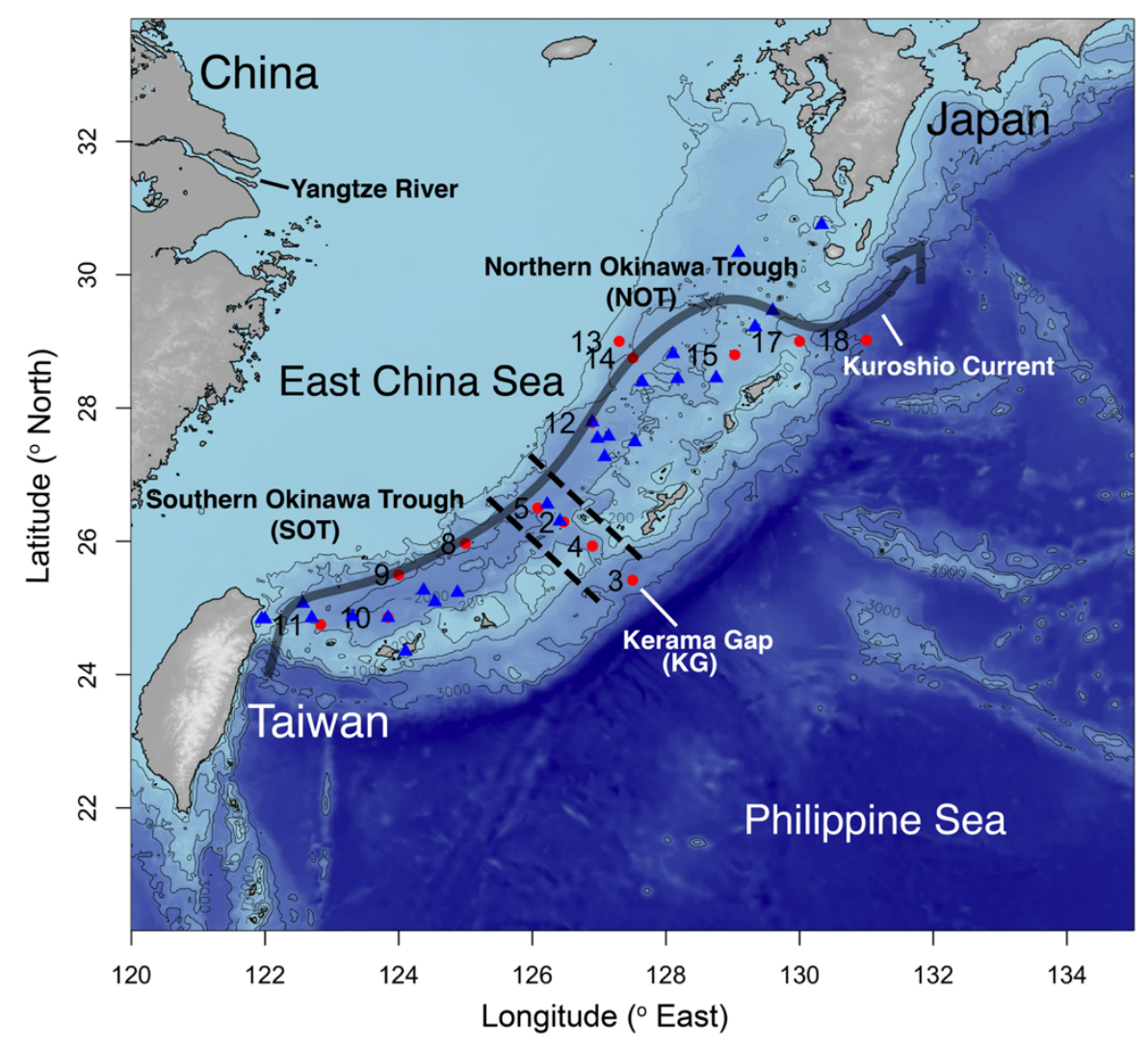

Figure 1. Sampling locations in the Okinawa Trough. Numbered red circles denote sampling stations where water was collected during the Japan Agency for Marine-Earth Science and Technology (JAMSTEC) MR17-03C cruise in May and June 2017. Blue triangles indicate active hydrothermal sites according to the InterRidge Vents Database v3.4 (https://ventsdata.interridge.org/ventfields-osm-map, accessed 05/08/2019). Bathymetry data was accessed and plotted through the function getNOAA.bathy in R package marmap. The $200,1000,2000$,

125 and $3000 \mathrm{~m}$ isobaths are plotted and labeled. Station 2 is at the ANA site of the Daisan-Kume Knoll, station 10 is at the Hatoma Knoll, station 11 is near the Dai-Yon Yonaguni Knoll, station 5 is near the Higa vent site, and station 12 is near the Iheya North vent field.

\section{Sample collection}

130 A Niskin rosette with 30 10-liter bottles and fitted with a conductivity-temperature-depth (CTD) probe (SBE 911plus, Sea-Bird Scientific, Bellevue, WA) was deployed at each cruise station to collect water from the subsurface chlorophyll maximum (SCM, 50-100 $\mathrm{m}$ ), the middle water column (mid, 700-1500 m), and approximately $10 \mathrm{~m}$ above the seafloor (bottom, 772-2957 m) (Supplemental Table 1). Surface seawater was collected

135 by bucket alongside the research vessel. Two replicates of 4.5 liters (surface) from separate bucket casts or 5 liters from separate Niskin bottles (SCM, mid, bottom) were sequentially filtered under a gentle vacuum through $10.0-\mu \mathrm{m}$ and $0.2-\mu \mathrm{m}$ pore-size 
Protist diversity and biogeography in the Okinawa Trough

polytetrafluoroethylene (PTFE) filters (Millipore, Burlington, MA). Filters were flashfrozen in liquid nitrogen and stored at $-80^{\circ} \mathrm{C}$. Temperature, salinity, dissolved oxygen,

140 fluorescence, and turbidity profiles were recorded by CTD probe at each station. CDOM and chemical analyses for nitrate, nitrite, $\mathrm{NH}_{4}$, phosphate, silicate and total carbon were performed by Marine Works Japan Ocean Chemistry Analysis Section onboard with water collected by Niskin bottle.

\section{DNA extraction and sequencing library preparation}

DNA was extracted from PTFE filters $(n=224$, two replicates of two filter pore-sizes at four depths from 14 stations) following manufacturer's protocols for the DNeasy PowerWater Kit (Qiagen, Hilden, Germany) including the optional heating step for 10 min at $65^{\circ} \mathrm{C}$ to fully lyse cells. Sequencing libraries were prepared following the Illumina

150 16S Metagenomic Sequencing Library Preparation manual, but with universal eukaryotic primers for the V4 region of the eukaryotic 18S rRNA gene (F: CCAGCASCYGCGGTAATTCC [23], R: ACTTTCGTTCTTGATYR [24]) and $58^{\circ} \mathrm{C}$ annealing temperature in the initial PCR. Amplicon libraries were sequenced by the Okinawa Institute of Science and Technology (OIST) DNA Sequencing Section on the 155 Illumina MiSeq platform with 2x300-bp v3 chemistry. Amplification and sequencing were successful for 211 samples and at least one replicate succeeded for each sample type.

\section{Amplicon sequence analysis}

Sequence data from each of four flow-cells were denoised separately using the Divisive 160 Amplicon Denoising Algorithm [25] through the DADA2 plug-in for QIIME 2 [26]. We analyzed amplicon sequence variants (ASVs) to maximize the amount of diversity included in the study [27] and detect changes in community composition that may not be apparent if analyzed at higher taxonomic levels. Denoised ASV tables were merged before taxonomy was assigned to ASVs with a naive Bayes classifier trained on the 165 Protist Ribosomal Reference (PR2) database [28] using the QIIME 2 feature-classifier plug-in [29]. We imported results into the R statistical environment [30] for further processing with the $\mathrm{R}$ package phyloseq [31]. Sequences were initially filtered to remove those that were not assigned taxonomy at the Kingdom level-likely data 
Protist diversity and biogeography in the Okinawa Trough

artifacts-and all metazoan sequences. We did not apply additional prevalence or

170 minimum abundance filtering since samples were from varied locations and depths, but the DADA2 algorithm discards singletons.

\section{Statistical analyses}

To test whether community composition varied significantly by depth, filter-size, region

175 or presence or absence of hydrothermal influence in bottom water samples, we computed the Aitchison distance between samples, which minimizes compositional bias inherent in metabarcoding data [32], and performed Permutational Multivariate Analyses of Variance (PERMANOVA, 999 permutations) with the adonis2 function from the $\mathrm{R}$ package vegan [33]. We further used pairwise PERMANOVA (999 permutations) to test

180 which regions differed in community composition from each other. Because stations 3 and 18 were much deeper than other stations (Supplemental Table 1), we used midwater samples from these stations in the bottom-water analyses and excluded these stations from the mid-water analyses. This is further justified because the mid-water samples at these stations were from the salinity layer contributing to bottom waters at

185 the other stations (Supplemental Figure 2). To determine if environmental variables contributed to changes in community composition, we performed Redundancy Analysis (RDA) and applied ANOVA to RDA results to test whether RDA models were statistically significant and which environmental variables significantly contributed to variation in community composition [34]. Before performing RDA, we tested for

190 collinearity of environmental variables by computing Pearson correlation coefficients between environmental variables in each depth layer (Supplemental Figure 3). If the absolute value of correlation coefficients was greater than 0.8 , we only included one of the correlated variables in the RDA for that depth [35]. We further applied variance partitioning on variables that significantly contributed to variation in community

195 composition to determine the percent of variation attributable to each variable [36]. Lastly, we used the DESeq2 Bioconductor package [37] to determine which ASVs were differentially abundant in bottom water from sites influenced by hydrothermal activity compared to bottom water at other sites. The data and code necessary to reproduce the statistical analyses are available on github 
bioRxiv preprint doi: https://doi.org/10.1101/714816; this version posted December 2, 2019. The copyright holder for this preprint (which was not certified by peer review) is the author/funder, who has granted bioRxiv a license to display the preprint in perpetuity. It is made available under aCC-BY 4.0 International license.

Protist diversity and biogeography in the Okinawa Trough

200 (https://github.com/maggimars/OkinawaTroughProtists), including an interactive online document: https://maggimars.github.io/OkinawaTroughProtists/OTprotists.html.

\section{Results}

\section{Protist diversity in the Okinawa Trough}

205 Overall, 31.5 million sequencing reads were generated for this study, with 34,631$421,992$ sequencing reads per sample (mean $=144,604)$. All sequences are available from the NCBI Sequencing Read Archive with accession PRJNA546472. Following denoising, 16.8 million sequences remained, with 1,724-215,842 sequences per sample $($ mean $=77,342)$. A total of 22,656 unique ASVs were identified in our dataset,

210 with 49-1,906 observed ASVs per sample (mean = 730). We used pairwise Wilcox tests on observed richness and Shannon indices to determine whether alpha diversity differed between depths or was influenced by hydrothermal activity. The SCM had significantly higher richness than surface, mid, and bottom waters $(p<0.001$, Supplemental Figure 4A). Shannon indices for SCM and surface samples were not

215 significantly different but were both significantly higher than for mid and bottom waters $(p<0.001$, Supplemental Figure 4B). Hydrothermally influenced bottom waters at stations 11, 10, and 2 did not have significantly different observed richness or Shannon indices from other bottom water samples (Supplemental Figure 4C-D).

Samples clustered by depth in a Principal Coordinate Analysis (PCoA) of

220 Aitchison distance between samples, with SCM and surface samples clustering separately from mid and bottom water samples on the primary axis (Figure 2). SCM and surface samples further separated on the secondary axis, but mid and bottom water samples clustered together. PERMANOVA results were significant at $p<0.05$ when performed by depth layer on all samples. When samples from each depth were

225 analyzed separately, samples clustered by filter pore-size on the primary axis for surface and SCM samples, and on the secondary axis for mid and bottom water samples (Supplemental Figure 5A-D), but PERMANOVA results by filter pore-size were not statistically significant.

Surface samples were dominated by Dinoflagellata, Haptophyta, and Radiolaria 230 in the larger size-fraction and Dinoflagellata, Haptophyta, Ochrophyta and MAST groups 
Protist diversity and biogeography in the Okinawa Trough

in the smaller size-fraction (Figure 3). In the SCM, Dinoflagellata, Haptophyta, Ochrophyta and Radiolaria were most abundant in the larger fraction and Chlorophyta, Dinoflagellata, Haptophyta, Ochrophyta, Radiolaria, and MAST groups were most abundant in the smaller size-fraction. The mid and bottom water samples were 235 dominated by Dinoflagellata and Radiolaria in both size-fractions. Interestingly, bottom water samples from hydrothermally influenced stations $(2,10,11)$ included noticeably higher proportions of Ciliophora, Ochrophyta, and MAST groups.

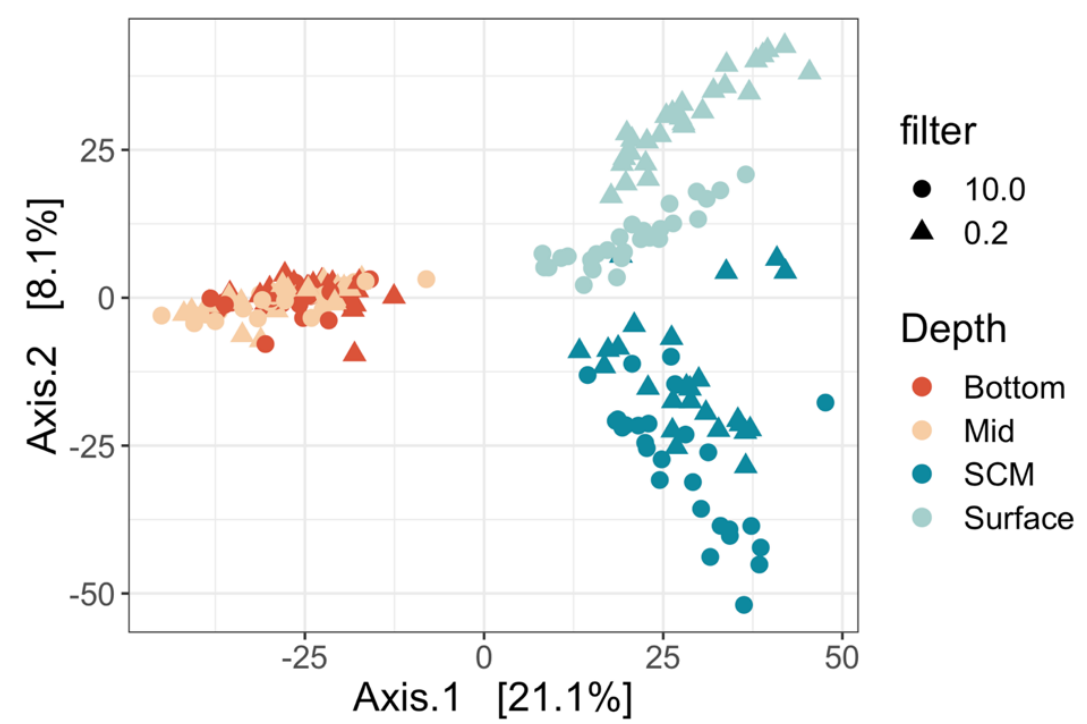

240 Figure 2. Principal coordinates analysis of Aitchison distances between size-fractionated protist communities from four depths in the Okinawa Trough. Point color indicates the depth layer from which samples were collected and point shape reflects the filter pore-size used to collect samples in $\mu \mathrm{m}$. Samples cluster in three main groups by depth: surface, subsurface chlorophyll maximum (SCM), and mid/bottom waters. Community composition was significantly different by depth layer (PERMANOVA, 999 permutations, $p<0.05$ ). 
Protist diversity and biogeography in the Okinawa Trough

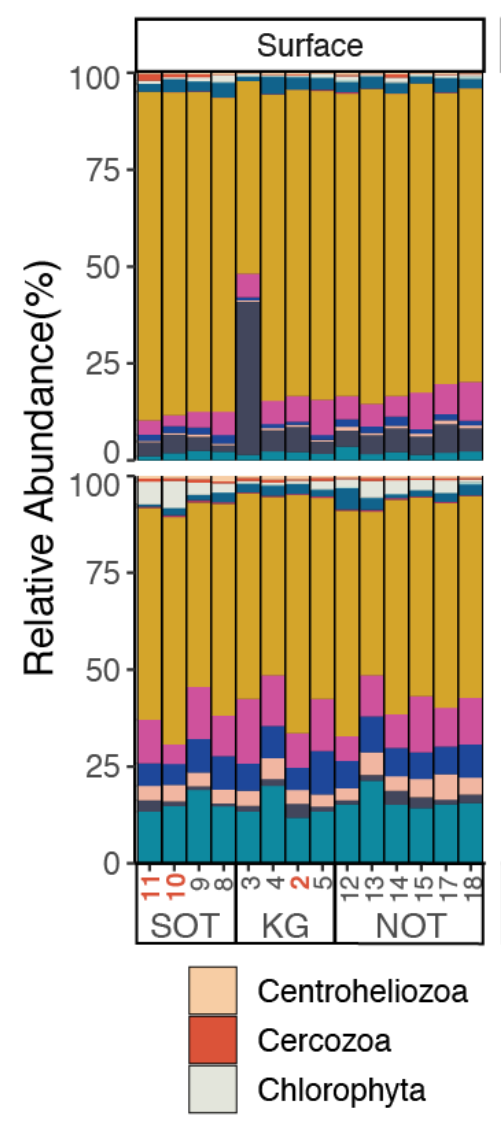

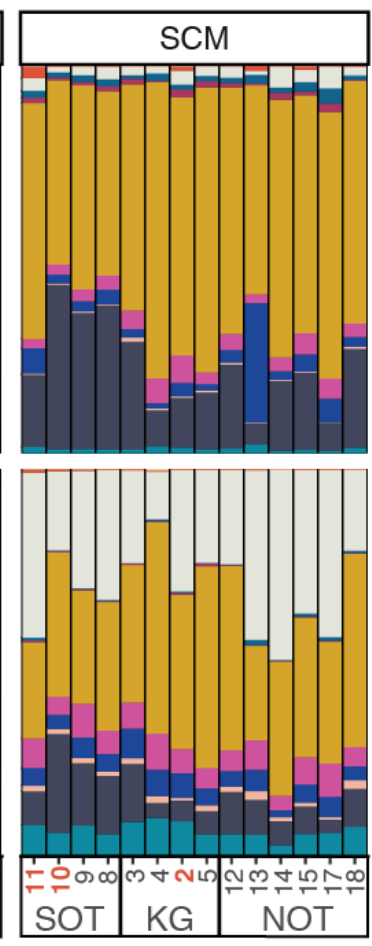

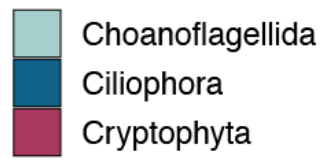

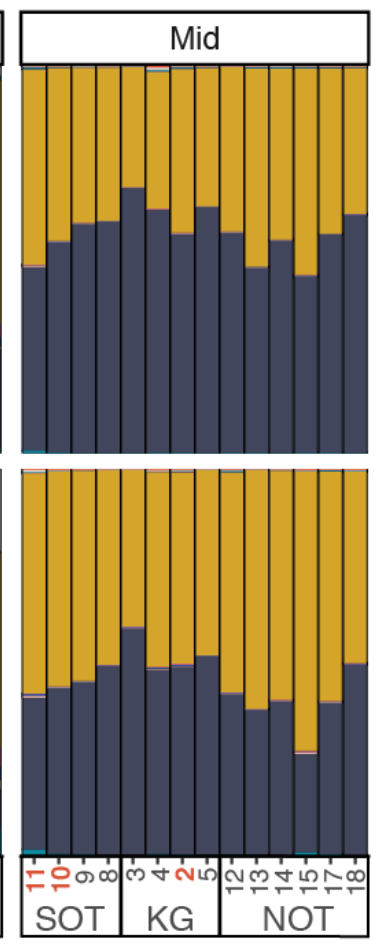

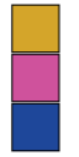

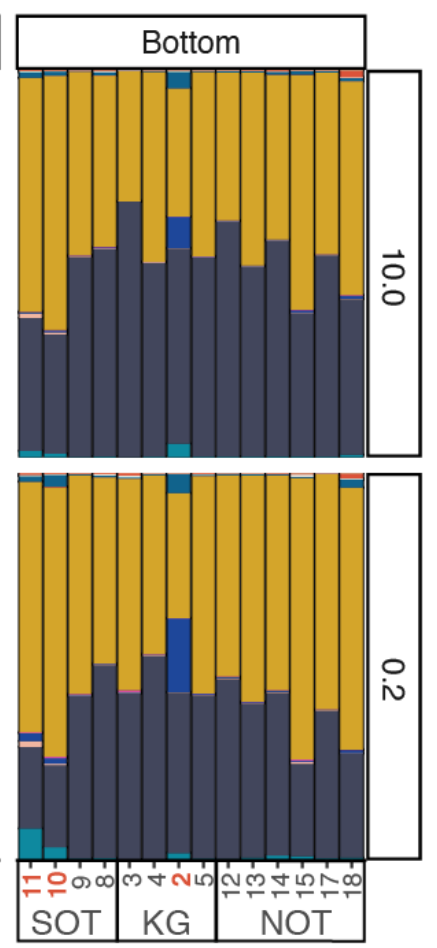

\begin{tabular}{l}
$\square$ \\
\hline \\
\hline \\
Radicozoa \\
MAST
\end{tabular}

Figure 3. Relative abundance of major protist groups in size-fractionated samples from 250 four depths in the Okinawa Trough (OT). Sampling stations are ordered on the $x$-axis from south to north: Southern Okinawa Trough (SOT) stations include 11, 10, 9, and 8; Kerama Gap (KG) stations include 3, 4, 2, and 5; Northern Okinawa Trough (NOT) stations include 12, 13, $14,15,17$, and 18 . The plot is faceted by sampling depth (columns) and filter pore-size in $\mu \mathrm{m}$ (rows). When replicates were available for a particular station/depth/filter combination, replicates

255 were collapsed and represented with a single stacked bar. Regional community differences are not visible at the high taxonomic level represented in the plot, but there are visible differences by depth and filter pore-size. Hydrothermally influenced sites include station 10 at the Hatoma Knoll vent field, station 11 near the Dai-Yon Yonaguni Knoll, and station 2 at the ANA vent at the Daisan-Kume Knoll (highlighted in red).

\section{Protist biogeography in the Okinawa Trough}

To investigate biogeography of protist communities in the OT, we merged smaller and larger size-fractions for replicates and subset samples by depth. Permutational Multivariate Analyses of Variance (PERMANOVA, 999 permutations) by region (SOT,

$265 \mathrm{KG}, \mathrm{NOT}$ ) on the Aitchison distances between samples were significant in surface, SCM, mid-water, and bottom-water samples $(p<0.05)$. Among surface samples, NOT and SOT samples were significantly different from KG samples, but NOT and SOT 
Protist diversity and biogeography in the Okinawa Trough

samples were not significantly different from each other. Among SCM samples, NOT and SOT samples were significantly different, but neither were significantly different

270 from KG samples. For mid- and bottom-water samples, all pairwise comparisons were significant.

Redundancy analysis was applied to evaluate the contribution of environmental factors to regional differences in protist community composition (Figure 4). ANOVA results for the surface water RDA model were significant $(p<0.05)$ and ANOVA by

275 environmental variable showed that temperature significantly affected community composition. Variance partitioning indicated that temperature explained $2.6 \%$ of variance, whereas region explained 5.5\% (multiple testing adjusted $\mathrm{R}^{2}$ ). Dissolved Oxygen (DO) was correlated with temperature (Supplemental Figure 3) in surface samples, so DO was excluded from the model. The RDA model for SCM samples

280 additionally included the depth of the SCM at each site and no variables covaried. The SCM model results were not significant $(p=0.182)$; variance partitioning indicated region explained $3.4 \%$ of variance. In the mid-water samples, temperature covaried with DO, CDOM, nitrate, silicate, and phosphate and, of these, only temperature was included in the RDA model. The mid water model results were statistically significantly

285 and salinity and $\mathrm{NH}_{4}$ both significantly contributed to model results. Variance partitioning showed that region explained $7.3 \%$ of variance, whereas $\mathrm{NH}_{4}$ and salinity explained 2.4 and $1.2 \%$, respectively. In bottom water samples, temperature covaried with CDOM, nitrate, phosphate, silicate and, of these, only temperature was included in the RDA model. The RDA model was statistically significant and turbidity, $\mathrm{NH}_{4}$, temperature and

290 DO significantly contributed to model results. Variance partitioning indicated that region explained $6.9 \%$ of variance, whereas turbidity explained $3.2 \%, \mathrm{NH}_{4}$ explained $1.4 \%$, temperature explained $1.5 \%$ and DO explained $1.7 \%$. It should be noted that DO and temperature had very high variance inflation factors in this test (>150), even though their correlation coefficient was $<0.8$. 
A. Surface

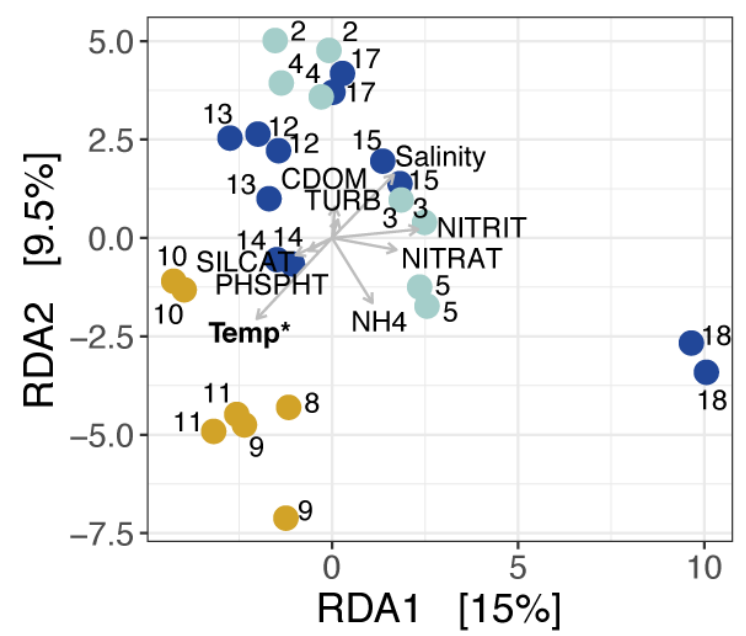

C. Mid

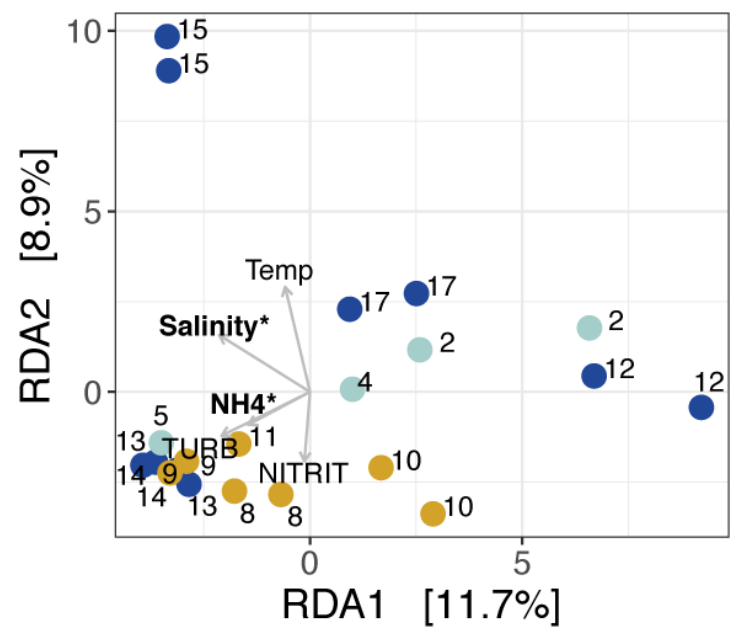

B. SCM

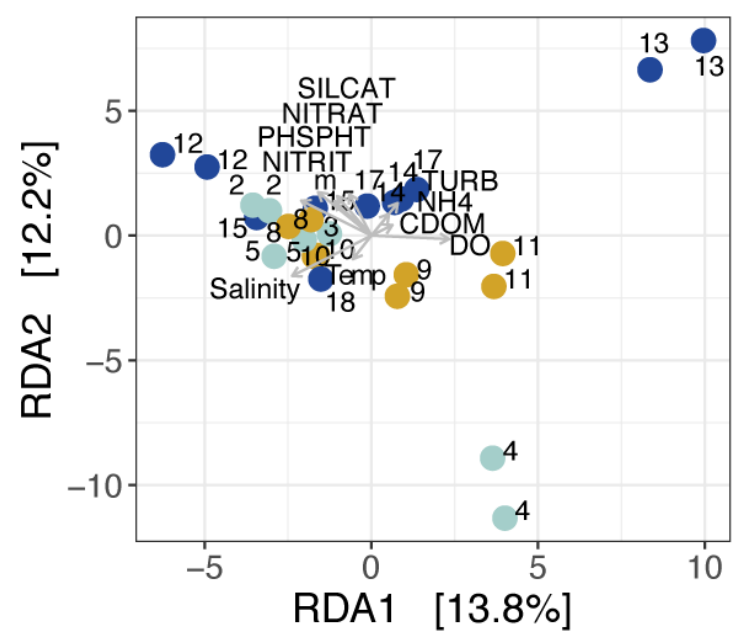

D. Bottom

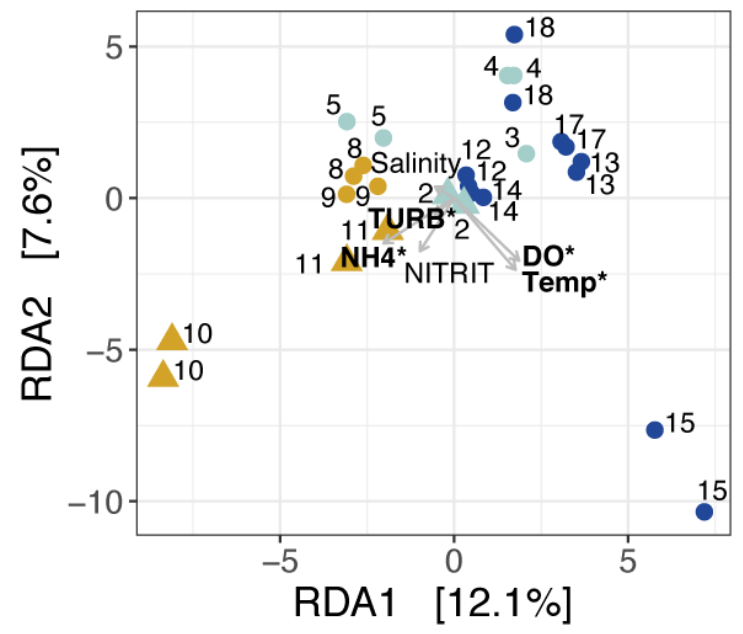

KG

NOT

$\Delta$ Hydrothermal Site (Bottom only)

Figure 4. Distance based redundancy analysis (RDA) of protist communities and explanatory environmental variables for four depth-layers in the Okinawa Trough. If environmental variables covaried with a Pearson correlation coefficient greater than 0.8 (absolute value), only one covarying variable was included in the analysis; temperature covaried with dissolved oxygen (DO) in surface waters, no variables covaried at the SCM, temperature covaried with DO, colored dissolved organic matter (CDOM), nitrate (NITRAT), silicate (SILICAT), and phosphate (PHSPHT) in the mid-water column, and temperature covaried with CDOM, nitrate, phosphate, silicate in the bottom waters. The RDA model results were significant in surface (A), mid (C), and bottom waters (D) and variables that significantly contributed to variation in community composition are in bold and marked with an asterisk (ANOVA, $p<0.05$ ). KG is the Kerama Gap (light blue), NOT is the Northern Okinawa Trough (dark blue), and SOT is the Southern Okinawa Trough (gold). For bottom water samples (D), hydrothermally influenced sites are demarcated as triangles. 
Protist diversity and biogeography in the Okinawa Trough

\section{Protist communities at hydrothermal vent sites}

To evaluate the effect of hydrothermal activity on protist diversity, we first checked whether alpha diversity was significantly different at hydrothermally influenced sites;

315 hydrothermal influence did not significantly increase or decrease observed richness or Shannon indices in bottom water samples (Supplemental Figure 4C-D). To determine if hydrothermal influence altered community composition, we performed PERMANOVA by presence or absence of hydrothermal influence on the Aitchison distances between bottom water samples; community compositions at hydrothermally influenced sites were 320 significantly different from other bottom water samples $(p=0.001)$.

Lastly, we investigated if there were protist ASVs specifically associated with hydrothermally influenced sites by testing for differentially abundant ASVs in the hydrothermally influenced bottom samples compared to the rest of the bottom water samples using DESeq2 [37]. An ASV was considered significantly differentially

325 abundant when the False Discovery Rate adjusted $p$-value was less than or equal to 0.01. Overall, 45 ASVs were significantly differentially abundant between samples from hydrothermally influenced sites and the rest of the bottom water samples. Of the differentially abundant ASVs, 30 were more abundant at sites with hydrothermal influence than at the other sites, and included Dinophyceae, Syndiniales,

330 Chrysophyceae, MAST, RAD-A and RAD-B Radiolarians, Oligohymenophorea and Spirotrichea ciliates, and Picozoa ASVs (Figure 5). 
Protist diversity and biogeography in the Okinawa Trough

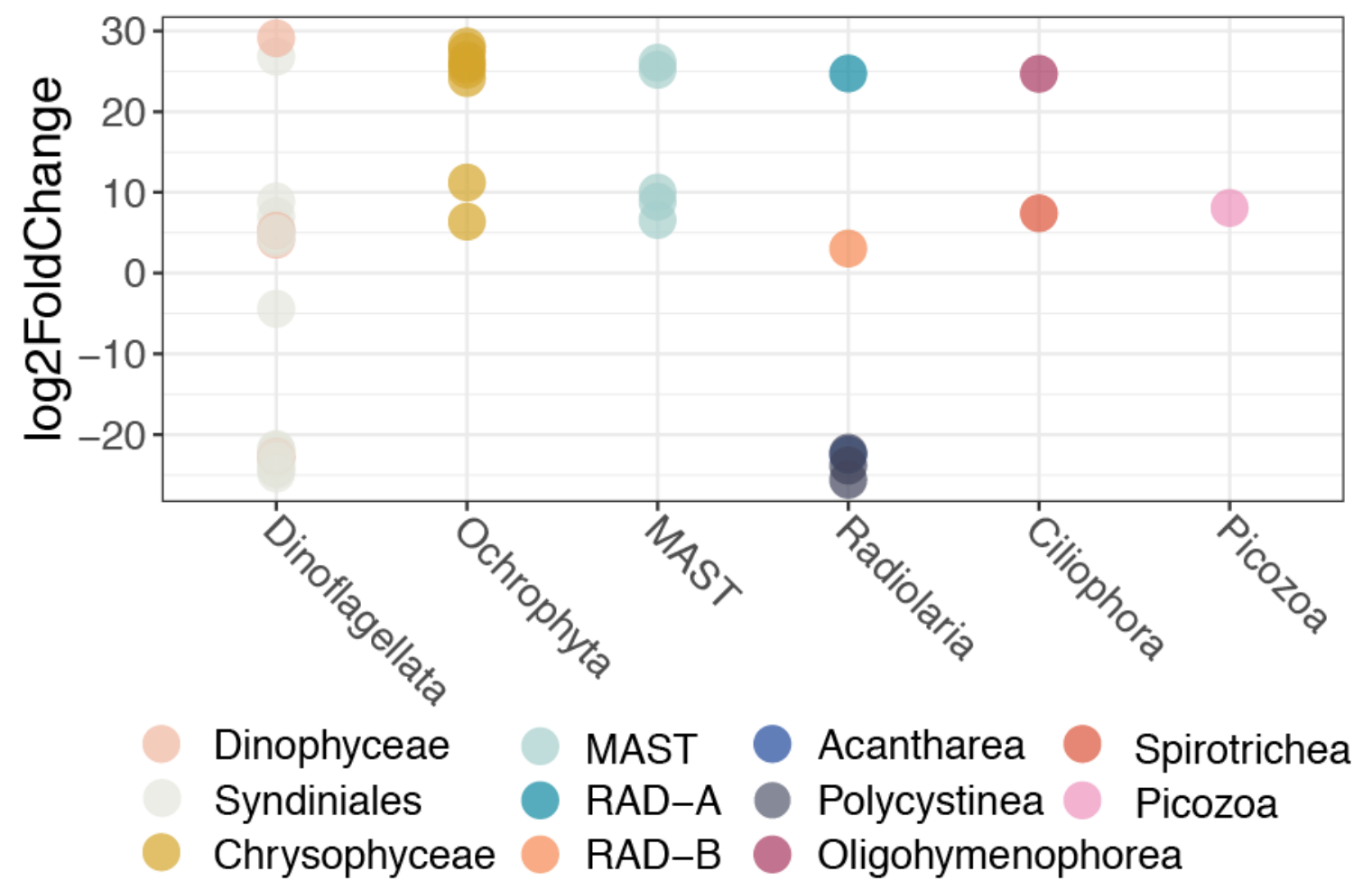

Figure 5. Log2 fold-change of significantly differentially abundant ASVs in bottom water 335 influenced by hydrothermal activity. The DESeq function in the DESeq2 package was used to test whether ASVs were significantly more (positive log2 fold-change) or less (negative log2 fold-change) abundant in hydrothermally influenced bottom water samples from Stations 10, 11, and 2 compared to bottom water samples from the other sites. Each point represents a single significantly differentially abundant ASV and taxonomic groupings are indicated on the $\mathrm{x}$-axis

340 and by color. ASVs were considered significantly differentially abundant if False Discovery Rate adjusted $p$-values were $<0.01$.

\section{Discussion}

Due to their small size, protists, like bacteria, face few dispersal barriers in the ocean

345 [38]. In addition, rapid asexual reproduction in many protists, as well as the ability to form resting cysts, increases their dispersal potential. As a result, many protists are cosmopolitan, suggesting that global protist diversity is low while local diversity in any given place is relatively high $[39,40]$. Whether or not this is the case depends largely on how protist species and diversity are defined. For example, if a higher level of genetic diversity is included in a species definition, global diversity will be lower. Conversely, if less genetic differentiation is included in a species definition, global diversity will be higher [41]. This has been demonstrated in bacteria through studies of biogeography at deep sea hydrothermal vents: only when microdiversity-diversity at the single 
Protist diversity and biogeography in the Okinawa Trough

nucleotide polymorphism level-is considered does geographic population structure

355 emerge [17, 42]. By analyzing ASVs, which capture the highest amount of diversity available in metabarcoding datasets, we investigated whether biogeographic patterns exist among protists in the Okinawa Trough in regard to regional ocean circulation patterns, water mass composition, and hydrothermal influence. Our results demonstrate relatively weak biogeography in surface waters through to the mid-water column, but

360 show strong regional differentiation of protist communities in deeper water. In addition, protist communities in bottom waters affected by hydrothermal vent activity were significantly different from communities in other bottom water samples.

\section{Protist biogeography in the Okinawa Trough}

365 Consistent with previous studies on protist biogeography, the strongest overall influence on community composition was the depth sampled [43]. Depth-dependent diversity patterns were similar to metabarcoding results from other regions, with higher diversity in the surface and SCM than the meso- and bathypelagic [8, 43]. In addition, overall community structure by depth was comparable to global patterns: Dinoflagellata,

370 Haptophyta, Ochrophyta, Picozoa, Radiolaria and Marine Stramenopiles (MASTs) were abundant in the surface and SCM while Dinoflagellata and Radiolaria dominated in the meso- and bathypelagic [5].

While depth was the strongest determinant of community composition overall, there were significant regional differences in community composition in all depth layers

375 and region contributed more to variance than environmental variables. The Okinawa Trough is divided into Southern (SOT) and Northern (NOT) regions based on the location of the Kerama Gap (KG) and bottom water characteristics [10]. The fastflowing, northward Kuroshio current is the major oceanographic feature in the upper water column [9]. Intermediate water consistently enters the trough through the KG, 380 whereas surface water regularly enters and occasionally exits [11, 44]. Regional differences in protist community composition are mostly consistent with these prevailing current patterns. In surface and mid-water samples, NOT and SOT communities were both significantly different from KG samples, but NOT and SOT communities were not different from each other in the surface waters, where the Kuroshio current is strongest. 
Protist diversity and biogeography in the Okinawa Trough

385 At the SCM, NOT and SOT samples differed significantly but KG samples did not differ from NOT or SOT samples. These results may be due, in part, to Changjiang (a.k.a. Yangtze) Diluted Water (CDW) and Kuroshio water were mixing at the continental shelf near station 13. The Changjiang/Yangtze is the longest river in China and transports terrestrial nutrients and anthropogenic pollutants into the East China Sea, causing 390 eutrophication that regularly triggers causes diatom blooms [45]. CTD and nutrient measurements at station 13 showed decreased subsurface salinity and increased nutrient concentrations and chlorophyll fluorescence compared to other sampling sites (Supplemental Figure 6). In addition, there as was an increased contribution of Bacillariophyceae diatoms (Ochrophyta, Figure 4) to the community composition at 395 station 13.

The regional pattern in protist community was most robust in the bottom waters, where protist communities were significantly distinct in each region and where each region has distinct water mass composition; bottom water in the SOT is comprised of 45\% low-salinity North Pacific Intermediate Water (NPIW) and 55\% high-salinity South

400 China Sea Intermediate Water (SCSIW), while KG bottom water is $75 \%$ NPIW and 25\% SCSIW and NOT bottom water is 65\% NPIW, 35\% SCSIW [10]. Similarly, Agogue et al. (2011) found water mass composition was the strongest predictor of prokaryotic community composition in the Atlantic Ocean [6], and Pernice et al. (2016) found water mass composition was the strongest predictor of protist community composition in the 405 deep waters of the Atlantic, South and Equatorial Pacific, and Indian oceans [5]. Water masses in the ocean may either act as geographic boundaries to dispersal or select for microbes adapted to specific environmental conditions [5, 6]. If differences in community composition were due to distinct chemical properties of water masses, it would support the latter [6]. In the OT, salinity is the major marker for water mass composition [10],

410 and the salinities measured during our sampling were consistent with those reported for the different water mass compositions (Supplemental Figure 2A-B, [10]). However, salinity did not significantly contribute to variation in community composition in the bottom waters of the OT (Figure 4D). Therefore, our results support the idea that particular water mass histories influence community composition and suggest that water masses may act as barriers to microbial dispersal [6]. 


\section{Protist diversity and biogeography in the Okinawa Trough}

\section{Protist communities at hydrothermal vent sites}

The protist communities in samples from hydrothermally influenced sites were significantly different from the communities in bottom waters at sites without

420 hydrothermal influence. Furthermore, environmental factors that significantly contributed to variation in community composition in bottom waters—turbidity, $\mathrm{NH}_{4}$-are related to hydrothermal activity in the OT, where vents resuspend overlying terrigenous material creating turbid vent plumes [16]. Syndiniales, Ciliophora, and MAST (Marine Stramenopiles) ASVs were significantly enriched in hydrothermally influenced OT

425 bottom waters, which is consistent with previous work comparing protists in bottom waters with varying proximity to hydrothermal vents [3]; Ochrophyta, environmental clades of Radiolaria, and Picozoa ASVs were additionally enriched near hydrothermally influenced sites in this study (Figures 2, 5). Quantitative models of deep-water circulation suggest that vents in back-arc basins, such as the Okinawa Trough, are well-

430 connected, but basin to basin dispersal may be restricted [12]. A remaining question, then, is whether protists enriched near vents in the Okinawa Trough are similar to protists in other hydrothermal systems and other marine ecosystems.

Dinoflagellate ASVs made up the majority of differentially abundant ASVs at hydrothermally influenced sites (22 out of 45, Figure 5) and half of these were more

435 abundant near vents. Among the enriched ASVs, eight are in the parasitic order Syndiniales, including group I (clades 2 and 7) and group II (clades 1, 6, 12, 13, 14, and 16). The remaining enriched dinoflagellate ASVs belong to the Order Dinophyceae but could not be further classified. Group II Syndiniales are common in sunlit, surface waters, whereas group I is common in suboxic and anoxic ecosystems. However, both

440 groups I and II are found in surface and deep water and have clades that have only been recovered from suboxic or anoxic ecosystems [46]. The majority of the enriched Syndiniales ASVs shared $100 \%$ identity with GenBank sequences ( $\mathrm{nr} / \mathrm{nt}$, accessed $5 / 16 / 2019$, [47, 48]) from a wide variety of ecosystems throughout the global ocean, including surface waters near the poles, mesopelagic water near the California coast,

445100 and 200 m oxygenated and micro-oxic North Atlantic waters, and at the sediment interface near the Juan de Fuca Ridge vent system $[49,50]$; the Syndinales ASVs 
Protist diversity and biogeography in the Okinawa Trough

enriched in hydrothermally influenced samples clearly derive from cosmopolitan organisms. Although they are not restricted to vent systems, parasitic Syndiniales do seem to thrive in vent systems and may take advantage of increased host availability in

450 such regions [51].

Ochrophyta accounted for the second-most enriched ASVs in hydrothermally influenced samples (Figure 5). The enriched Ochrophyta ASVs belong to several clades within the order Chrysophyceae. Two belong to clades with unknown morphology made up of environmental sequences (clades EC2H and EC2I) recovered from a diverse 455 array of marine and freshwater environments [52]. The remaining ASVs belong to the genus Paraphysomonas, which are colorless phagotrophs that are globally distributed in freshwater, marine, and soil ecosystems and have previously been recovered from vent sites [53]. Although several of the enriched ASVs share $>99 \%-100 \%$ identity with previously published vent-associated sequences [53], they are equally similar to

460 sequences recovered from many other marine environments, indicating that these enriched ASVs also derive from cosmopolitan organisms.

Five of the ASVs enriched in hydrothermally influenced samples belong to marine stramenopile lineages-MAST-1, -7, -8 (Figure 5). Most of what is known about MAST lineages has been learned through environmental molecular surveys. Aggregate

465 analyses of sequences collected through such studies have found that MAST-1, -7, and -8 are highly diverse, globally-distributed, and abundant in surface waters $[54,55]$. Culture-independent techniques have further demonstrated that MAST-1 [56], MAST-7 [57], and MAST-8 [54] are bactivorous flagellates. Therefore, it is likely that the MAST ASVs enriched in hydrothermally influenced samples represent cosmopolitan 470 bacterivores. Indeed, MAST ASVs from this study each share 99\% (MAST-7) to 100\% (MAST-1, -8) identity with multiple sequences recovered from surface waters, including from (anoxic) Saanich Inlet, Vancouver, Canada [58], the Scotian Shelf in the North Atlantic [59], and the Southern Ocean [60].

The RAD-A and RAD-B radiolarian groups represent environmental clades that 475 have no morphological description—other than being picoplankton—or known ecological roles [61]. The RAD-A ASV enriched in hydrothermally influenced samples (Figure 5) shares > 99\% identity with many GenBank sequences recovered from oxic 


\section{Protist diversity and biogeography in the Okinawa Trough}

and anoxic waters globally, including the Cariaco basin in the Caribbean Sea [50], the Gulf Stream [49], and the South East Pacific [62]. The enriched RAD-B ASV shares

$480100 \%$ identity with multiple sequences recovered from the East Pacific Rise (1500 m and $2500 \mathrm{~m}$ ), the Arctic Ocean (500 m), oxygenated water in the Cariaco Basin [50], the Juan de Fuca Ridge [63], and the Southern Ocean [64]. While the radiolarian ASVs enriched in hydrothermally influenced samples appear to be cosmopolitan, it is notable that identical and similar sequences have repeatedly been isolated from vent fields and

485 anoxic regions.

Previous studies indicated Ciliophora are abundant in sediments and bacterial mats near hydrothermal vents [65-67]. It is unsurprising, then, that two Ciliophora ASVs were significantly more abundant in hydrothermally influenced samples (Figure 5). The enriched Spirotrichea ASV was classified to genus level by our classifier and belongs to

490 Leegaardiella, a recently described genus collected in the North Atlantic [68]. The Leegardiella ASV shared 100\% coverage and identity with one sequence in GenBankan uncultured eukaryote clone recovered from $2500 \mathrm{~m}$ at the East Pacific Rise-and had greater than $99 \%$ shared identity with another sequence recovered from the East Pacific Rise, also from 2500 m [49]. However, the Leegardiella ASV also had 100\%

495 coverage and $>99 \%$ identity matches with several sequences recovered from Arctic surface water [69]. This Leegardiella ASV may, therefore, derive from a widely distributed genus that opportunistically becomes more abundant at vent sites. The Oligohymenophorea ASV belongs to the environmental OLIGO 5 clade, but did not have $>96 \%$ identity matches to any sequences in GenBank; the closest match was to

500 an uncultured eukaryote clone recovered from $500 \mathrm{~m}$ depth off the coast of California [49]. The EukRef-Ciliophora curated Oligohymenophorea phylogeny groups the OLIGO 5 clade with the subclass Scuticiliatia [70]. Interestingly, Zhao and Zu (2016) also found Spirotrichea and Scuticiliatia enriched among ciliates found near a vent site in the Northern Okinawa Trough [71]. While spirotrich ciliates are generally bacterivores [65],

505 Scuticiliatia ciliates are known to be symbionts of aquatic organisms [72], including giant hydrothermal bivalves [3]. If the Scuticiliata ASV is a symbiont, it could provide some explanation as to why more similar sequences have not been recovered elsewhere; coevolution with a dispersal-limited host could also limit symbiont dispersal [73]. 


\section{Protist diversity and biogeography in the Okinawa Trough}

However, it is equally likely that sequences with high similarity to the Scuticiliata ASV

510 have not yet been recovered elsewhere simply due to insufficient sampling.

A single ASV enriched near vent sites belonged to Picozoa (Figure 5). The first Picozoa species was described in 2013 [74] and Picozoa ecology remains poorly resolved. Information regarding their distribution derives from environmental molecular surveys, which have established five clades within Picozoa. While all Picozoa are

515 marine, biogeographical patterns vary between clades: clade BP2 has only been found in surface waters, group 2 is mostly found in deep waters, and the other three groups are globally distributed throughout the water column [75]. The enriched Picozoa ASV belongs to one of the cosmopolitan clades (group 1). The sequence shares $100 \%$ identity with three others in Genbank, from a variety of environments-surface water in

520 the Arctic [76] and Southern [77] oceans, as well as mesopelagic water near southern California [49].

\section{Conclusions and future directions}

While the Okinawa Trough provides an ideal setting to investigate protist diversity and

525 biogeography, this study represents the first comprehensive survey of protists in the region. Our results show that protist communities largely reflect regional oceanography and are influenced by water mass composition in near-bottom waters. Disentangling environmental and geographic effects on communities is challenging since many variables, such as temperature, covary with latitude. However, region consistently

530 contributed more to variance in community composition than any environmental factors in this study. We additionally found distinct protist communities associated with hydrothermally influenced sites, with bacterivore, parasitic, and putatively symbiotic protists enriched in hydrothermally influenced bottom waters. The enriched protists were mostly globally distributed, and many were previously found at vent sites in other parts

535 of the world. These results emphasize the importance of the rare biosphere; most protists seem to be widely distributed, even if rare, and can become opportunistically more abundant under certain conditions. A major limitation of metabarcoding studies with DNA is that it is impossible to know whether sequences derive from actively metabolizing cells, dead or inactive cells, or even environmental DNA; future studies will 


\section{Protist diversity and biogeography in the Okinawa Trough}

540 benefit from incorporating methods that better delineate metabolic state. Additionally, metabarcoding studies suffer from focusing on a short sequence to assess diversity; metagenomic and metatranscriptomic approaches are becoming increasingly feasible for large-scale protist surveys, which will allow for finer resolution of diversity. In the future, comparisons between the Okinawa Trough and other hydrothermal regions will

545 continue to advance our understanding of important protists in hydrothermal ecosystems and how hydrothermal activity influences protist diversity and biogeography in the global ocean.

\section{Acknowledgements}

550 We thank the captain and crew of the JAMSTEC R/V Mirai for their assistance and support in sample collection. Hiroyuki Yamamoto, Hiromi Watanabe, Dhugal Lindsay, Mary M. Grossmann, and Yuko Hasagawa were instrumental in organizing and facilitating cruise sampling and Otis Brunner substantially contributed to seawater filtration. We are further grateful to Hiromi Watanabe for helping to access and interpret

555 environmental data and for comments on the manuscript. We thank the OIST DNA sequencing section (Onna, Okinawa) for carrying out the sequencing. This work was funded by the Marine Biophysics Unit of the Okinawa Institute of Science and Technology Graduate University. MMB was supported by a Japan Society for the Promotion of Science DC1 graduate student fellowship.

\section{References}

1. Massana R. Eukaryotic picoplankton in surface oceans. Annu Rev Microbiol 2011; 65: $91-$ 110.

2. Edgcomb VP. Marine protist associations and environmental impacts across trophic levels in the twilight zone and below. Curr Opin Microbiol 2016; 31: 169-175.

565 3. Sauvadet A-L, Gobet A, Guillou L. Comparative analysis between protist communities from the deep-sea pelagic ecosystem and specific deep hydrothermal habitats. Environ Microbiol 2010; 12: 2946-2964.

4. de Vargas C, Audic S, Henry N, Decelle J, Mahé F, Logares R, et al. Ocean plankton. Eukaryotic plankton diversity in the sunlit ocean. Science 2015; 348: 1261605. 


\section{Protist diversity and biogeography in the Okinawa Trough}

570 5. Pernice MC, Giner CR, Logares R, Perera-Bel J, Acinas SG, Duarte CM, et al. Large variability of bathypelagic microbial eukaryotic communities across the world's oceans. ISME J 2016; 10: 945-958.

6. Agogué H, Lamy D, Neal PR, Sogin ML, Herndl GJ. Water mass-specificity of bacterial communities in the North Atlantic revealed by massively parallel sequencing. Mol Ecol $575 \quad 2011 ; 20: 258-274$.

7. Lima-Mendez G, Faust K, Henry N, Decelle J, Colin S, Carcillo F, et al. Ocean plankton. Determinants of community structure in the global plankton interactome. Science 2015; 348: 1262073.

8. Giner CR, Balagué V, Pernice MC, Duarte CM, Gasol JM, Logares R, et al. Marked changes in diversity and relative activity of picoeukaryotes with depth in the global ocean.

9. Barkley RA. The Kuroshio current. Science Journal 1970; 6: 54-60.

10. Nakamura H, Nishina A, Liu Z, Tanaka F. Intermediate and deep water formation in the Okinawa Trough. Journal of Geophysical Research Oceans 2013.

11. Na H, Wimbush M, Park J-H, Nakamura H, Nishina A. Observations of flow variability through the Kerama Gap between the East China Sea and the Northwestern Pacific. J Geophys Res C: Oceans 2014; 119: 689-703.

12. Mitarai $\mathrm{S}$, Watanabe $\mathrm{H}$, Nakajima $\mathrm{Y}$, Shchepetkin AF, McWilliams JC. Quantifying dispersal from hydrothermal vent fields in the western Pacific Ocean. Proc Natl Acad Sci U S A 2016; 113: 2976-2981.

13. Beaulieu SE, Szafranski K. InterRidge Global Database of Active Submarine Hydrothermal Vent Fields, Version 3.4. http://vents-data.interridge.org. Accessed 5 May 2019.

14. Makabe A., Tsutsumi S., Chen C., Torimoto J., Matsui Y., Shibuya T., Miyazaki J., Kitada K., Kawagucci S. Discovery of New Hydrothermal Vent Fields in the Mid- and southernOkinawa Trough. Goldschmidt Abstracts. 2016. p 1945.

15. Miyazaki J, Kawagucci S, Makabe A, Takahashi A, Kitada K, Torimoto J, et al. Deepest and hottest hydrothermal activity in the Okinawa Trough: the Yokosuka site at Yaeyama Knoll. $R$ Soc Open Sci 2017; 4: 171570.

16. Toki T, Itoh M, Iwata D, Ohshima S, Shinjo R, Ishibashi J-I, et al. Geochemical characteristics of hydrothermal fluids at Hatoma Knoll in the southern Okinawa Trough.

600 Geochem J 2016; 50: 493-525.

17. Mino S, Makita H, Toki T, Miyazaki J, Kato S, Watanabe H, et al. Biogeography of Persephonella in deep-sea hydrothermal vents of the Western Pacific. Front Microbiol 2013; 4: 107. 


\section{Protist diversity and biogeography in the Okinawa Trough}

18. Dick GJ. The microbiomes of deep-sea hydrothermal vents: distributed globally, shaped locally. Nat Rev Microbiol 2019; 17: 271-283.

19. Nagata T, Tamburini C, Arístegui J, Baltar F, Bochdansky AB, Fonda-Umani S, et al. Emerging concepts on microbial processes in the bathypelagic ocean - ecology, biogeochemistry, and genomics. Deep Sea Research Part II: Topical Studies in Oceanography . 2010. , 57: 1519-1536

610 20. Zhang X, Sun Z, Fan D, Xu C, Wang L, Zhang X, et al. Compositional characteristics and sources of DIC and DOC in seawater of the Okinawa Trough, East China Sea. Cont Shelf Res 2019; 174: 108-117.

21. Konno U, Tsunogai U, Nakagawa F, Nakaseama M, Ishibashi J-I, Nunoura T, et al. Liquid CO 2 venting on the seafloor: Yonaguni Knoll IV hydrothermal system, Okinawa Trough.

$615 \quad$ Geophys Res Lett 2006; 33: 725.

22. Nakajima R, Yamamoto H, Kawagucci S, Takaya Y, Nozaki T, Chen C, et al. Post-drilling changes in seabed landscape and megabenthos in a deep-sea hydrothermal system, the Iheya North field, Okinawa Trough. PLoS One 2015; 10: e0123095.

23. Stoeck T, Bass D, Nebel M, Christen R, Jones MDM, Breiner H-W, et al. Multiple marker parallel tag environmental DNA sequencing reveals a highly complex eukaryotic community in marine anoxic water. Mol Ecol 2010; 19 Suppl 1: 21-31.

24. Mars Brisbin M, Mesrop LY, Grossmann MM, Mitarai S. Intra-host Symbiont Diversity and Extended Symbiont Maintenance in Photosymbiotic Acantharea (Clade F). Front Microbiol 2018; 9: 1998.

625 25. Callahan BJ, McMurdie PJ, Rosen MJ, Han AW, Johnson AJA, Holmes SP. DADA2: Highresolution sample inference from Illumina amplicon data. Nat Methods 2016; 13: 581-583.

26. Bolyen E, Rideout JR, Dillon MR, Bokulich NA, Abnet CC, Al-Ghalith GA, et al. Reproducible, interactive, scalable and extensible microbiome data science using QIIME 2. Nat Biotechnol 2019.

630 27. Callahan BJ, McMurdie PJ, Holmes SP. Exact sequence variants should replace operational taxonomic units in marker-gene data analysis. ISME J 2017; 11: 2639-2643.

28. Guillou L, Bachar D, Audic S, Bass D, Berney C, Bittner L, et al. The Protist Ribosomal Reference database (PR2): a catalog of unicellular eukaryote small sub-unit rRNA sequences with curated taxonomy. Nucleic Acids Res 2013; 41: D597-604.

635 29. Bokulich NA, Kaehler BD, Rideout JR, Dillon M, Bolyen E, Knight R, et al. Optimizing taxonomic classification of marker-gene amplicon sequences with QIIME 2's q2-featureclassifier plugin. Microbiome 2018; 6: 90. 


\section{Protist diversity and biogeography in the Okinawa Trough}

30. R Core Team. R: A language and environment for statistical computing. 2018.

31. McMurdie PJ, Holmes S. phyloseq: an R package for reproducible interactive analysis and graphics of microbiome census data. PLoS One 2013; 8: e61217.

32. Gloor GB, Macklaim JM, Pawlowsky-Glahn V, Egozcue JJ. Microbiome Datasets Are Compositional: And This Is Not Optional. Front Microbiol 2017; 8.

33. Oksanen J, Guillaume Blanchet F, Friendly M, Kindt R, Legendre P, McGlinn D, et al. vegan: Community Ecology Package. R package version 2.5-4. 2019.

645 34. Legendre P, Oksanen J. Testing the significance of canonical axes in redundancy analysis. Methods Ecol Evol 2011.

35. Ramette A. Multivariate analyses in microbial ecology. FEMS Microbiol Ecol 2007; 62: 142160.

36. Legendre P. Studying beta diversity: ecological variation partitioning by multiple regression 650 and canonical analysis. J Plant Ecol 2008; 1: 3-8.

37. Love MI, Huber W, Anders S. Moderated estimation of fold change and dispersion for RNAseq data with DESeq2. Genome Biol 2014; 15: 550.

38. Whittaker KA, Rynearson TA. Evidence for environmental and ecological selection in a microbe with no geographic limits to gene flow. Proc Natl Acad Sci U S A 2017; 114: 26516552656.

39. Finlay BJ. Global dispersal of free-living microbial eukaryote species. Science 2002; 296: 1061-1063.

40. Fenchel T, Finlay BJ. The Ubiquity of Small Species: Patterns of Local and Global Diversity. Bioscience 2004; 54: 777-784.

660 41. Caron DA. Past President's address: protistan biogeography: why all the fuss? J Eukaryot Microbiol 2009; 56: 105-112.

42. Mino S, Nakagawa S, Makita H, Toki T, Miyazaki J, Sievert SM, et al. Endemicity of the cosmopolitan mesophilic chemolithoautotroph Sulfurimonas at deep-sea hydrothermal vents. ISME J 2017; 11: 909-919.

665 43. Countway PD, Gast RJ, Dennett MR, Savai P, Rose JM, Caron DA. Distinct protistan assemblages characterize the euphotic zone and deep sea $(2500 \mathrm{~m})$ of the western North Atlantic (Sargasso Sea and Gulf Stream). Environ Microbiol 2007; 9: 1219-1232.

44. Jin B, Wang G, Liu Y, Zhang R. Interaction between the East China Sea Kuroshio and the Ryukyu Current as revealed by the self-organizing map. J Geophys Res 2010; 115: 937.

670 45. Lin YC, Chung CC, Gong GC, Chiang KP. Diversity and abundance of haptophytes in the East China Sea. Aquat Microb Ecol 2014; 72: 227-240. 


\section{Protist diversity and biogeography in the Okinawa Trough}

46. Guillou L, Viprey M, Chambouvet A, Welsh RM, Kirkham AR, Massana R, et al. Widespread occurrence and genetic diversity of marine parasitoids belonging to Syndiniales (Alveolata). Environ Microbiol 2008; 10: 3349-3365.

675 47. Camacho C, Coulouris G, Avagyan V, Ma N, Papadopoulos J, Bealer K, et al. BLAST+: architecture and applications. BMC Bioinformatics 2009; 10: 421.

48. Clark K, Karsch-Mizrachi I, Lipman DJ, Ostell J, Sayers EW. GenBank. Nucleic Acids Res 2016; 44: D67-72.

49. Lie AAY, Liu Z, Hu SK, Jones AC, Kim DY, Countway PD, et al. Investigating microbial eukaryotic diversity from a global census: insights from a comparison of pyrotag and fulllength sequences of 18S rRNA genes. Appl Environ Microbiol 2014; 80: 4363-4373.

50. Edgcomb V, Orsi W, Bunge J, Jeon S, Christen R, Leslin C, et al. Protistan microbial observatory in the Cariaco Basin, Caribbean. I. Pyrosequencing vs Sanger insights into species richness. ISME J 2011; 5: 1344-1356.

685 51. Moreira D, López-García P. Are hydrothermal vents oases for parasitic protists? Trends Parasitol 2003; 19: 556-558.

52. Scoble JM, Cavalier-Smith T. Scale evolution in Paraphysomonadida (Chrysophyceae): Sequence phylogeny and revised taxonomy of Paraphysomonas, new genus Clathromonas, and 25 new species. Eur J Protistol 2014; 50: 551-592.

53. Atkins MS, Teske AP, Anderson OR. A Survey of Flagellate Diversity at Four Deep-Sea Hydrothermal Vents in the Eastern Pacific Ocean Using Structural and Molecular Approaches. J Eukaryot Microbiol 2000; 47: 400-411.

54. Massana R, del Campo J, Sieracki ME, Audic S, Logares R. Exploring the uncultured microeukaryote majority in the oceans: reevaluation of ribogroups within stramenopiles. ISME J 2014; 8: 854-866.

55. Massana R, Castresana J, Balagué V, Guillou L, Romari K, Groisillier A, et al. Phylogenetic and ecological analysis of novel marine stramenopiles. Appl Environ Microbiol 2004; 70: 3528-3534.

56. Massana R, Terrado R, Forn I, Lovejoy C, Pedrós-Alió C. Distribution and abundance of uncultured heterotrophic flagellates in the world oceans. Environ Microbiol 2006; 8: 15151522.

57. Frias-Lopez J, Thompson A, Waldbauer J, Chisholm SW. Use of stable isotope-labelled cells to identify active grazers of picocyanobacteria in ocean surface waters. Environ Microbiol 2009; 11: 512-525.

705 58. Orsi W, Song YC, Hallam S, Edgcomb V. Effect of oxygen minimum zone formation on 


\section{Protist diversity and biogeography in the Okinawa Trough}

communities of marine protists. ISME J 2012; 6: 1586-1601.

59. Dasilva CR, Li WKW, Lovejoy C. Phylogenetic diversity of eukaryotic marine microbial plankton on the Scotian Shelf Northwestern Atlantic Ocean. J Plankton Res 2014; 36: 344363.

710 60. Massana R, Guillou L, Díez B, Pedrós-Alió C. Unveiling the organisms behind novel eukaryotic ribosomal DNA sequences from the ocean. Appl Environ Microbiol 2002; 68: 4554-4558.

61. Not F, Gausling R, Azam F, Heidelberg JF, Worden AZ. Vertical distribution of picoeukaryotic diversity in the Sargasso Sea. Environ Microbiol 2007; 9: 1233-1252.

715 62. Shi XL, Marie D, Jardillier L, Scanlan DJ, Vaulot D. Groups without cultured representatives dominate eukaryotic picophytoplankton in the oligotrophic South East Pacific Ocean. PLOS One 2009; 4: e7657.

63. Jungbluth SP, Grote J, Lin H-T, Cowen JP, Rappé MS. Microbial diversity within basement fluids of the sediment-buried Juan de Fuca Ridge flank. ISME J 2013; 7: 161-172.

720 64. Clarke LJ, Bestley S, Bissett A, Deagle BE. A globally distributed Syndiniales parasite dominates the Southern Ocean micro-eukaryote community near the sea-ice edge. ISME J 2019; 13: 734-737.

65. Coyne KJ, Countway PD, Pilditch CA, Lee CK, Caron DA, Cary SC. Diversity and distributional patterns of ciliates in Guaymas Basin hydrothermal vent sediments. $J$ Eukaryot Microbiol 2013; 60: 433-447.

66. Pasulka A, Hu SK, Countway PD, Coyne KJ, Cary SC, Heidelberg KB, et al. SSU-rRNA Gene Sequencing Survey of Benthic Microbial Eukaryotes from Guaymas Basin Hydrothermal Vent. J Eukaryot Microbiol 2019; 66: 637-653.

67. López-García P, Vereshchaka A, Moreira D. Eukaryotic diversity associated with carbonates and fluid-seawater interface in Lost City hydrothermal field. Environ Microbiol 2007; 9: 546-554.

68. Santoferrara LF, Alder VV, McManus GB. Phylogeny, classification and diversity of Choreotrichia and Oligotrichia (Ciliophora, Spirotrichea). Mol Phylogenet Evol 2017; 112: 12-22.

735 69. Terrado R, Scarcella K, Thaler M, Vincent WF, Lovejoy C. Small phytoplankton in Arctic seas: vulnerability to climate change. Biodiversity 2013; 14: 2-18.

70. Boscaro V, Santoferrara LF, Zhang Q, Gentekaki E, Syberg-Olsen MJ, Del Campo J, et al. EukRef-Ciliophora: a manually curated, phylogeny-based database of small subunit rRNA gene sequences of ciliates. Environ Microbiol 2018; 20: 2218-2230. 


\section{Protist diversity and biogeography in the Okinawa Trough}

740 71. Zhao F, Xu K. Molecular diversity and distribution pattern of ciliates in sediments from deep-sea hydrothermal vents in the Okinawa Trough and adjacent sea areas. Deep Sea Res Part I 2016; 116: 22-32.

72. Fan X, Hu X, Al-Farraj SA, Clamp JC, Song W. Morphological description of three marine ciliates (Ciliophora, Scuticociliatia), with establishment of a new genus and two new species. Eur J Protistol 2011; 47: 186-196.

73. Peek AS, Feldman RA, Lutz RA, Vrijenhoek RC. Cospeciation of chemoautotrophic bacteria and deep sea clams. Proc Natl Acad Sci U S A 1998; 95: 9962-9966.

74. Seenivasan R, Sausen N, Medlin LK, Melkonian M. Picomonas judraskeda gen. et sp. nov.: the first identified member of the Picozoa phylum nov., a widespread group of picoeukaryotes, formerly known as 'picobiliphytes'. PLoS One 2013; 8: e59565.

75. Moreira D, López-García P. The rise and fall of Picobiliphytes: how assumed autotrophs turned out to be heterotrophs. Bioessays 2014; 36: 468-474.

76. Terrado R, Medrinal E, Dasilva C, Thaler M, Vincent WF, Lovejoy C. Protist community composition during spring in an Arctic flaw lead polynya. Polar Biol 2011; 34: 1901-1914.

755 77. Díez B, Pedrós-Alió C, Massana R. Study of genetic diversity of eukaryotic picoplankton in different oceanic regions by small-subunit rRNA gene cloning and sequencing. Appl Environ Microbiol 2001; 67: 2932-2941. 